\title{
Poetas Italianos do SÉculo XX: Breve Antologia
}

\author{
Tradução de Maurício Santana Dias
}

NOTADO TRADUTOR As traduções aqui apresentadas são os primeiros resultados, ainda provisórios, do projeto de edição de uma ampla antologia de Poetas italianos do século $X X$, que será devidamente acompanhada de notas e introdução. Por ora, no âmbito específico desta revista, creio que o simples cotejo entre os textos italiano e português seja suficiente para, senão explicitar, ao menos delinear uma implícita poética tradutória. Os poemas $A$ ilha, de Giuseppe Ungaretti, O porco, de Umberto Saba, A espera, de Camillo Sbarbaro, e os Fragmentos líricos XI e XXXIV. de Clemente Rebora, foram publicados no livro de Alfonso Berardinelli citado nas referências bibliográficas. Oparaíso sobreos telhados, de Cesare Pavese, faz parte do volume Trabalhar cansa, do mesmo autor, em fase de publicação pela editora Cosacnaify. As demais traduções são inéditas. 


\section{Giuseppe Ungaretti}

\section{L'ISOLA}

A una proda ove sera era perenne

Di anziane selve assorte, scese,

E s'inoltrò

E lo richiamò rumore di penne

Ch'erasi sciolto dallo stridulo

Batticuore dell'acqua torrida,

E una larva (languiva

E rifioriva) vide;

Ritornato a salire vide

Ch'era una ninfa e dormiva

Ritta abbracciata a un olmo.

In sé da simulacro a fiamma vera

Errando, giunse a un prato ove

L'ombra negli occhi s'addensava

Delle vergini come

Sera appiè degli ulivi;

Distillavano i rami

Una pioggia pigra di dardi,

Qua pecore s'erano appisolate

Sotto il liscio tepore,

Altre brucavano

La coltre luminosa;

Le mani del pastore erano un vetro

Levigato da fioca febbre.

| 1925|

\section{A ILHA}

A uma costa onde a tarde era perene De antigas e absortas selvas veio

Ese adentrou

E um farfalhar de penas o atraiu

Ao desatar-se da estrídula

Pulsação das águas tórridas,

Euma imagem (murchava

E refloria) viu;

Voltando para o alto viu

Que era uma ninfa e dormia

Erguida, abraçada a um olmo.

Em si, de simulacro a vera chama

Errando, deu num prado onde

A sombra nos olhos das virgens

Se adensava como

Noite ao pé de oliveiras;

Destilavam os ramos

Uma chuva tarda de dardos,

Ovelhas cochilavam espalhadas

Sob o tênue tepor,

Outras mordiam

$A$ alfombra luminosa;

De vidro temperado em febre fraca

Eram as māos do pastor.

$|19 \cdot 2.5|$ 
SENZA PIÙ PESO

a Ottone Rosai

Per um Iddio che rida come um bimbo, Tanti gridi di passeri,

Tante danze nei rami,

Un’anima si fa senza più peso, I prati hanno una tale tenerezza, Tale pudore negli occhi rivive,

Le mani come foglie

S'incartano nell'aria...

Chi teme più, chi giudica?

|19:34|

\section{JÁ SEM PESO}

a Ottone Rosai

Para um Deus que sorria feito criança, Tantos gritos de pássaros,

Tantas danças nos ramos,

Uma alma se conforma já sem peso, As campinas têm tamanha ternura, Tal compostura nos olhos revive,

As mãos como folhas

Se encantam na brisa...

Quem teme ainda, quem julga?

| 19:34| 


\section{Guido Gozzano}

\section{LA PIÙ BELLA!}

Ma bella più di tutte l'Isola Non-Trovata: quella che il Re di Spagna s'ebbe da suo cugino

il Re di Portogallo con firma sugellata e bulla del Pontefice in gotico latino.

L'Infante fece vela pel regno favoloso, vide le Fortunate: Iunonia, Gorgo, Hera

e il Mare di Sargasso e il Mare Tenebroso quell' isola cercando... Ma l'isola non c'era.

Invano le galee panciute a vele tonde, le caravelle invano armarono la prora: con pace del Pontefice l'isola si nasconde e Portogallo e Spagna la cercano tuttora.

II

L'isola esiste. Appare talora di lontano tra Teneriffe e Palma, soffusa di mistero:
“...l'Isola Non-Trovata!” Il buon Canarïano dal Picco alto di Teyde l'addita al forestiero.

La segnano le carte antiche dei corsari: ... Hifola da-trovarfi?... Hifola pellegrina?...

È l'isola fatata che scivola sui mari; talora i naviganti la vedono vicina...

Radono con le prore quella beata riva: tra fiori mai veduti svettano palme somme,

odora la divina foresta spessa e viva, lacrima il cardamomo, trasudano le gomme...

S’annuncia col profumo, come una cortigiana, l'Isola Non-Trovata... Mas, se il piloto avanza,

rapida si dilegua come parvenza vana, si tinge dell'azzurro color di lontananza...

|191:3| 


\section{A MAIS BELA!}

Bonita mais que todas a Ilha Não-Encontrada: essa que o Rei de Espanha obteve de seu primo

o Rei de Portugal, com firma carimbada e bula do Pontífice em gótico latino.

O Infante fez-se à vela ao reino fabuloso, viu-se nas Fortunadas: Junônia, Gorgo, Hera,

viu o Mar de Sargaço e aquele Tenebroso em torno à sua ilha... que lá se desfizera.

Em vão as galés gordas de velas todas plenas, em vão as caravelas armaram suas proas:

com fleuma de Pontífice a ilha se aliena e Portugal e Espanha a buscam inda agora.

II

A ilha existe. Às vezes desponta no oceano, de Tenerife a Palma, difusa no mistério:
“... a Ilha Não-Encontrada!” O bom canariano do Pico alto de Teyde a indica ao forasteiro.

Registram-na os antigos roteiros dos corsários ... Ínsuapor-encontrar-se?... Ínsuaque peregrina?...

É a ilha enfeitiçada rolando pelos mares; às vezes navegantes a vêem, cristalina...

Raspam-na com a proa sua margem furtiva: de flores nunca vistas despontam palmas régias,

milodores exalaa espessa selva viva, choramos cardamomos, transpiram claras héveas...

Se exibe perfumada, como uma cortesã, a Ilha Não-Encontrada... Mas, se o piloto avança,

rápida se dissolve qual aparência vā, de um tom de azul se tinge, azul cor de distância. 


\section{Umberto Saba}

\section{LA CAPRA}

Ho parlato a una capra.

Era sola sul prato, era legata.

Sazia d'erba, bagnata

dalla pioggia, belava.

Quell'uguale belato era fraterno al mio dolore. Ed io risposi, prima per celia, poi perché il dolore è eterno, ha una voce e non varia.

Questa voce sentiva gemere in una capra solitaria.

In una capra dal viso semita sentiva querelarsi ogni altro male, ogni altra vita.

|1910|

\section{A CABRA}

Falei com uma cabra.

Estava só, num prado, estava atada.

Já saciada, banhada

pela chuva, berrava.

Seu monótono balido era irmão

da minha dor. E eu respondi, primeiro por burla, depois porque a dor é eterna, tem uma voz, não várias.

Esta voz eu sentia gemendo numa cabra solitária.

Em uma cabra de rosto semita sentia debater-se todo o mal, toda outra vida.

| 1910| 


\section{IL MAIALE}

La broda, fior di sudiciume, è pura solo quanto il suo istinto n'è affamato; strilla come il bambino sculacciato, se allontani da lui la sua lordura.

Certo per lui grande ventura è quello che per me, per un mio pensiero, è strazio: che non si chieda perchè lo vuol bello di pinguedine, e il più pasciuto e sazio, la massaia che scaccia il poverello; ch'egli, come ogni vita, ignori a cosa poi gioverà quando sarà perfetto. Ma io, se riguardando in lui mi metto, io sento nelle sue carni il coltello, sento quell'urlo, quella spaventosa querela, quando al gruppo un cane abbaia, e la massaia ride dalla soglia.

Solo in me mette un impetuosa voglia di piangere quel suo beato aspetto.

\section{|191:3|}

\section{O PORCO}

O caldo, flor de podridão, é puro

somente enquanto $o$ instinto se contenta;

grita como menino e se arrebenta

se dele lhe tiramos o monturo.

Aquilo que para ele é grande sorte, para mim, num lampejo, é sofrimento: não saber o porquê de o querer forte e cheio de fartura, corpulento, a serva que escorraça o pobrezinho; ou que ele, como toda criatura, ignore o que será ao ser perfeito. Mas se nele, ao olhá-lo, me converto, eu sinto na sua carne a rasgadura, ouço o berro, o grunhido, o burburinho assustador, quando o cachorro late, e a criada gargalha da soleira.

Só em mim serpenteia essa vontade de prantear o seu bendito aspecto.

[191:3] 


\section{Clemente Rebora}

\section{FRAMMENTI \\ LIRICI XI}

O carro vuoto sul binario morto, ecco per te la merce rude d'urti e tonfi. Gravido ora pesi sui telai tesi;

ma nei ràntoli gonfi si crolla fumida e viene annusando con fàscino orribile la macchina ad aggiogarti.

Via dal tuo spazio assorto all'aspro rullare d'acciaio al trabalzante stridere dei freni, incatenato nel gregge per l'immutabile legge del continuo aperto cammino: e trascinato tramandi e irrigidito rattieni le chiuse forze inespresse su ruote vicine e rotaie incongiungibili e oppresse, sotto il cielo che balzàno nel labirinto dei giorni nel bivio delle stagioni contro la noia sguinzaglia l'eterno, verso l'amore pertugia l'esteso, e non muore e vorrebbe, e non vive e vorrebbe, mentre la terra gli chiede il suo verbo e appassionata nel volere acerbo paga col sangue, sola, la sua fede.

|1913|

\section{FRAGMENTOS LÍRICOS XI}

Ó vagão vazio sobre o trilho morto, eis a mercadoria de entrechoques e baques. Cheio agora pesas sobre traves tensas; mas em roucos arranques desloca-se fumegante e vem farejando com tétrico brilho a máquina a subjugar-te. Partes de teu ponto absorto e vais no áspero rolar do aço sacolejando ao atrito dos freios, encadeado ao rebanho por uma lei sem tamanho que mantém aberto o caminho: e arrastado transportas e enrijecido nāo soltas as forças inexprimidas nas rodas parelhas e linhas inconjugáveis e oprimidas sob o céu que extravagante no labirinto dos dias no oscilar das estações contra o tédio desata a eternidade, rumo ao amor perfura o espaço extenso,

e não morre e queria, e não vive e queria, enquanto a terra lhe pede o seu verbo e apaixonada no querer acerbo paga com sangue, sozinha, sua crença.

| 1913| 


\section{FRAMMENTI}

\section{LIRICI XXXIV}

Scienza vince natura:

è gloria. Immane ferve

e di macchine suona e di monete

l'uman contrasto,

mentre in disparte l'umiltà dei vinti

geme o s'invischia, e vana

la melodia silvana

inascoltata giace.

Oh per le vie all'alba

fulmineo ridestarsi, quando - uccelli dei nidi cittadini per l'aria dai camini

vólano le sirene

negl'incensi del fumo

chiamando al buon lavoro!

Evia si lancia il giorno

d'ora in ora al meriggio,

e giù per la sua china

a foggiar cose e pensieri

con intrecciate vicende

con risonanti movenze,

fin che la sera il gran pàlpito accoglie

e ne respira le voglie

fra il rincasar tumultuoso

che ai sobborghi nereggia negli echi

dell'ultime officine,

tra il brulicar delle forme

che s indugian più scaltre

nel tinnir luminoso dei corsi.

\section{FRAGMENTOS LÍRICOS XXXIV}

Ciência vence natureza:

é glória. Imensamente ferve

de máquinas ressoa e de moedas

o atrito humano,

enquanto, à parte, o coro dos vencidos

geme ou submerge, e sem sentido

a melodia da floresta

jaz sem ser ouvida.

Ó, nas ruas da aurora

um despertar de fogo,

quando - pássaros de ninhos urbanos -

por entre chaminés e canos

revoam altas as sirenes

em meio a incensos de fumaça

chamando para o bom trabalho!

E assim se desata a jornada

de hora em hora, até o meio-dia

e daí descendo pela encosta

a forjar coisas, pensamentos,

nas sucessões entrelaçadas

nos movimentos martelados,

até que a noite acolhe o peito que arde

aspirando sua força e sua vontade

na dura volta para casa

que nos subúrbios escurece entre os ecos

das mais tardias oficinas,

por entre o tremular das formas

que se demoram, precavidas,

no tinir luminoso de alamedas. 


\section{Camillo Sbarbaro}

\section{L’ATTESA}

Taci, anima mia. Son questi i tristi giorni in cui senza volontà si vive, i giorni dell'attesa disperata.

Come l'albero ignudo a mezzo inverno che s'attrista nell'ombra della corte, io non credo di mettere più foglie e dubito d'averle messe mai.

\section{Camminando solo}

tra la gente che m'urta e non mi vede, mi pare d'esser da me stesso assente. E m'accalco ad udire dov'è ressa, sosto dalle vetrine abbarbagliato e mi volgo al frusciare d'ogni gonna. Per la voce d'un cantastorie cieco per l'improvviso lampo d'una nuca mi sgocciolan dagli occhi sciocche lacrime mi s'accendon negli occhi cupidigie. Ché tutta la mia vita nei miei occhi ogni cosa che passa la commuove come debole vento un'acqua morta.

Non sono che uno specchio rassegnato che riflette ogni cosa per la via. In me stesso non guardo perché nulla vi troverei.

E, venuta la sera, nel mio letto mi stendo lungo come in una bara.

[191:3]

\section{A ESPERA}

\author{
Cala-te, alma minha. Eis aí os tristes \\ dias em que sem vontade se vive, \\ os dias da espera e do desespero. \\ Como o galho despido a meio inverno que \\ entristece no pátio desolado, \\ não creio que germinem novas folhas \\ e duvido jamais ter germinado.
}

\section{Andando sozinho} entre a gente que passa e não me vê, parece que de mim me sinto ausente.

E me aperto escutando onde há tumulto, aparvalhado paro nas vitrines e me viro ao roçar de qualquer saia. Pelo timbre de um cego cantador, pelo súbito brilho de uma nuca, escorrem de meus olhos tolas lágrimas, acende-se em meus olhos o desejo. Pois toda minha vida está nos olhos: cada coisa passageira a comove como a brisa que agita a água morta.

Eu sou como um espelho conformado que reflete cada ângulo da rua: a mim mesmo não miro porque nada encontraria.

E quando a noite desce à minha cama, me estendo, largo, como numa cova.

| 1913| 


\section{Eugenio Montale}

Parevafacile giuoco

mutare in nulla lo spazio

che m'era aperto, in un tedio

malcerto il certo tuo fuoco.

Ora a quel vuoto ho congiunto

ogni mio tardo motivo,

sull'arduo nulla si spunta

l'ansia di attenderti vivo.

La vita che dà barlumi

è quella che sola tu scorgi.

A lei ti sporgi da questa

finestra che non s'illumina.

|1939|

\section{LUNGOMARE}

Il soffio cresce, il buio è rotto a squarci, e l'ombra che tu mandi sulla fragile palizzata s'arriccia. Troppo tardi

se vuoi esser te stessa! Dalla palma tonfa il sorcio, il baleno è sulla miccia, sui lunghissimi cigli del tuo sguardo.

| 1940|

\section{Parecia fáciljogo}

transmudar em nada o espaço

que se me abria, em acídia

incerta o certo teu fogo.

Ora ao vazio conjuguei

todo meu tardo motivo, sobre o árduo nada desponta

a ânsia de esperar-te vivo.

A vida que dá vislumbres

é aquela que só tu percebes.

Para ela te inclinas desta

janela que nāo se alumbra.

[1939]

\section{BEIRA-MAR}

O sopro cresce, o breu se rompe em partes e a sombra que seu corpo imprime à frágil paliçada se encrespa. É muito tarde

querer ser você mesma! Da palmeira tomba o rato, o relâmpago é rastilho nos longuíssimos cílios de sua vista.

$|1940|$ 


\section{Eugenio Montale}

\section{LA FORMA DEL MONDO}

Se il mondo ha la struttura del linguaggio e il linguaggio ha la forma della mente la mente con i suoi pieni e i suoi vuoti è niente o quasi e non ci rassicura.

Così parlò Papirio. Era già scuro e pioveva. Mettiamoci al sicuro disse e affrettò il passo senza accorgersi che il suo era il linguaggio del delirio.

$[1971]$

\section{A FORMA DO MUNDO}

Se o mundo se estrutura na linguagem e a linguagem se forma como a mente a mente com seus cheios e vazios é nada ou quase e não nos assegura.

Assim falou Papírio. Era já escuro e chovia. Corramos ao abrigo disse e apressou o passo sem notar que a sua era a linguagem do delírio.

[1971] 


\section{ELOGIO DEL}

\section{NOSTRO TEMPO}

\author{
Non si può esagerare abbastanza \\ l'importanza del mondo \\ (del nostro, intendo) \\ probabilmente il solo \\ in cui si possa uccidere \\ con arte e anche creare \\ opere d'arte destinate a vivere \\ lo spazio di un mattino, sia pur fatto \\ di millenni e anche più. No, non si può \\ magnificarlo a sufficienza. Solo \\ ci si deve affrettare perché potrebbe \\ non essere lontana \\ l'ora in cui troppo si sarà gonfiata \\ secondo un noto apologo la rana.
}

|1977|

\section{ELOGIO DO}

NOSSO TEMPO
Não se pode exagerar o bastante

a importância do mundo

(do nosso, digo)

provavelmente o único

em que é possível matar

com arte e até criar

obras de arte fadadas a durar

o intervalo de um dia, ainda que feito

de milênios ou mais. Não, não se pode

exaltá-lo o suficiente. Só

é preciso ter pressa porque talvez

não esteja longe a manhã

em que demasiadamente inchará

segundo um famoso apólogo a rã. 


\section{Sandro Penna}

IV

Sotto il cielo di aprile la mia pace

è incerta. I verdi chiari ora si muovono

sotto il vento a capriccio. Ancora dormono l'acque ma, sembra, come ad occhi aperti.

Ragazzi corrono sull'erba, e pare che li disperda il vento. Ma disperso solo è il mio cuore cui rimane um lampo vivido (oh giovinezza) delle loro bianche camicie stampate sul verde.

[1)(1) 1914,1939$]$
IV

Sob o céu de abril minha paz é incerta. Agora os verdes claros se revolvem sob o volúvel vento. Ainda dormem as águas, mas como de olhos abertos.

Garotos correm na relva, e parece que o vento os dispersa. Porém disperso é só meu coração que guarda um brilho vivido (oh, juventude) de suas camisas brancas impressas no verde.

[DF:M-14, 1939] 


\section{Amelia Rosselli}

Facce appese, bronzi al muro, facce di bronzo, santi appesi

al muro in una camera solitaria in affitto, per quattro giorni aspetto. Una camera povera, sovraccarica di fiori di plastica, e leoni alla porta. Un mare trombante, e un paese grossolano, verdi porte all'aperto dietro la strada nuova, i monti inosservabili, la luce è un diadema. Le colline poi sono verdi cavalli, il galoppo un imbroglio, uno stratagemma per perdersi. Fa caldo ancora, e il cielo è macchiato di tombe oscure.

[12.

Rostos pensos, bronzes no muro, caras de bronze, santos pensos

no muro de um cômodo alugado e solitário, por quatro dias espero. Um cômodo pobre, atulhado de

flores

de plástico, e leões na porta. Um mar trovejante, e um país grosseiro, verdes portas ao ar livre atrás da estrada

nova, os montes indiscerníveis, a luz é um diadema. $E$ as colinas são verdes cavalos, o galope um imbróglio, um estratagema para perder-se. Faz calor ainda, e o céu está manchado de covas negras.

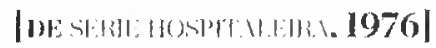




\section{Vittorio Sereni}

\section{PAURA SECONDA}

Niente ha di spavento

la voce che chiama me

proprio me

dalla strada sotto casa

in un'ora di notte:

è un breve risveglio di vento,

una pioggia fuggiasca.

Nel dire il mio nome non enumera

i miei torti, non mi rinfaccia il passato.

Con dolcezza (Vittorio

Vittorio) mi disarma, arma

contro me stesso me.

|D.1

\section{MEDO SEGUNDO}

Não há nenhum espanto

na voz que chama a mim

justo a mim

da rua de minha casa

a uma hora da noite:

é um breve despertar de vento, uma chuva furtiva.

Ao dizer meu nome não enumera meus erros, nāo me conîronta o passado.

Com doçura (Vittorio

Vittorio) me desarma, arma

contra mim mesmo a mim.

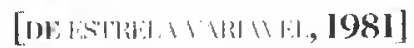




\section{Cesare Pavese}

\section{IL PARADISO \\ SUI TETTI}

Sarà un giorno tranquillo, di luce fredda come il sole che nasce o che muore, e il vetro chiuderà l'aria sudicia fuori del cielo.

Ci si sveglia un mattino, una volta per sempre, nel tepore dell'ultimo sonno: l'ombra sarà come il tepore. Empirà la stanza per la grande finestra un cielo piú grande. Dalla scala salita un giorno per sempre non verranno più voci, né visi morti.

Non sarà necessario lasciare il letto. Solo l'alba entrerà nella stanza vuota. Basterà la finestra a vestire ogni cosa di un chiarore tranquillo, quasi una luce. Poserà un'ombra scarna sul volto supino. I ricordi saranno dei grumi d'ombra appiattati cosi come vecchia brace nel camino. Il ricordo sarà la vampa che ancor ieri mordeva negli occhi spenti.

\section{O PARAÍSO SOBRE OS TELHADOS}

Será um dia tranqüilo, de luzes frias como o sol que levanta ou que morre, e o vidro fechará o ar imundo ao contato do céu.

Acordamos num dia, uma vez para sempre, na quentura de um último sono: a sombra será como a quentura. Entrará no quarto pela grande janela um céu mais extenso. Das escadas subidas num dia pra sempre não virão mais nem vozes nem rostos mortos.

Não será necessário deixar a cama. Só a aurora entrará nesse quarto vago. Bastará a janela a vestir cada coisa de clareza tranqüila, quase uma luz. Pousará uma sombra no rosto supino. As lembranças serão uns punhados de sombra consumidos, assim como velhas brasas na lareira. A lembrança será a chama que ainda ontem mordia nos olhos baços.

|11-16 DI.ANEIRO DI: 1940] 


\section{Patrizia Cavalli}

Adesso che il tempo sembra tutto mio e nessuno mi chiama per il pranzo e per la cena, adesso che posso rimanere a guardare come si scioglie una nuvola e come si scolora, come cammina un gatto per il tetto nel lusso immenso di una esplorazione, adesso che ogni giorno mi aspetta la sconfinata lunghezza di una notte dove non c'è richiamo e non c'è più ragione di spogliarsi in fretta per riposare dentro l'accecante dolcezza di un corpo che mi aspetta, adesso che il mattino non ha mai principio e silenzioso mi lascia ai miei progetti a tutte le cadenze della voce, adesso vorrei improvvisamente la prigione.

|DA 11. (11:1, 1981]

Agora que o tempo parece todo meu e ninguém me chama para o almoço ou o jantar, agora que posso permanecer olhando como uma nuvem se dissolve e como se desbota, como caminha um gato pelo teto no luxo imenso de uma exploração, agora que a cada dia me espera a interminável extensão de uma noite onde não há mais chamado nem há mais razão para despir-se depressa e repousar dentro da ofuscante doçura de um corpo que me espera, agora que a manhã já não tem princípio e silenciosa me abandona aos meus projetos a todas as cadências da voz, agora queria inesperadamente a prisão.

|DE: 1) (1), 1981| 


\section{Referências bibliográficas}

ANCESCHI, Luciano. Lirica del Novecento. Antologia di poesia italiana. A cura di Luciano Anceschi e Sergio Antonielli. Firenze: Vallecchi, 1953.

BERARDINELLI, Alfonso. Da poesia à prosa. Organização de Maria Betânia Amoroso. Tradução de Mauricio Santana Dias. São Paulo: Cosacnaify, 2007.

CAVALLI, Patrizia. Poesie (1974-1992). Tórino: Einaudi, 1002.

CONTINI, Gianfranco. Letteratura dell'Italia unita 1861-1968. Firenze: Sansoni, 1994.

CUCCHI, Maurizio, GIOVANARDI, Stefano. Poeti italiani del secondo Novecento. Mondadori: Milano, 2004.

DEBENEDETTI, Giacomo. Poesia italiana del Novecento. Milano: Garzanti, 1980.

GOZZANO, Guido. Tutte le poesie. A cura di Andrea Rocca. Introduzione di Marziano Guglielminetti. Milano: Meridiani Mondadori, 1980.

MENGALDO, Pier Vincenzo. Poeti italiani del Novecento. Milano: Mondadori, 1990.

MONTALE, Eugenio. Tutte le poesie. A cura di Giorgio Zampa. Milano: Mondadori. 1990.

PAVESE, Cesare. Le poesie. A cura di Mariarosa Masoero. Introduzione di Marziano Guglielminetti. Torino: Einaudi, 1998.

REBORA, Clemente. Le poesie (1913-1957). A cura di Vanni Scheiwiller con una nota di Gianni Mussini. Milano:

Vanni Scheiwiller, 1982.

ROSSELLI, Amelia. Le poesie. A cura di E. Tandello. Milano: Garzanti, 2007.

SABA, Umberto. Tutte le poesie. A cura di Arrigo Stara. Introduzione di Mario Lavagetto. Milano: Meridiani Mondadori, 2001.

SANGUINETI, Edoardo. Poesia italiana del Novecento. Torino: Einaudi, 1993.

SPAGNOLETTI, Giacinto. Antologia della poesia italiana (1909-1949). Bologna: Guanda, 1954

TESTA, Enrico. Dopo la lirica. Poeti italiani 1960-2000. Torino: Einaudi, 2005.

UNGARETTI, Giuseppe. Vita d'un uomo. Tutte le poesie. A cura di Leone Piccioni. Milano: Meridiani Mondadori, 2005. 